\title{
MOTIVOS FOLCLÓRICOS Y ESPECTÁCULO CABALLERESCO: EL PRÍNCIPE FELIPE EN LAS FIESTAS DE BINCHE EN 1549*
}

\author{
Alberto del Río Nogueras \\ Universidad de Zaragoza
}

Para Ana Bueno por tantos motivos

Tras la victoria de Mühlberg Carlos V invita al príncipe Felipe a personarse en sus dominios de los Países Bajos. El objetivo es doble, pues allí será jurado como heredero y se incorporará a la preparación de la estrategia familiar para la dieta de Augsburgo. En la ciudad austriaca el monarca pretende tratar con su hermano Fernando de Hungría el espinoso asunto de la sucesión en el trono imperial. En un viaje que se considera crucial para los destinos de la corona ${ }^{1}$, la Mitología y los ejemplos de historia profana y sagrada propor-

\footnotetext{
*Este trabajo se inscribe entre las actividades del grupo de investigación "Clarisel", financiado por el Departamento de Ciencia, Tecnología y Universidad del Gobierno de Aragón y por el Fondo Social Europeo.

${ }^{1}$ Los historiadores resaltan la importancia del viaje tanto en lo político como en el apartado de la formación personal del príncipe. Sus biógrafos suelen dedicar un capítulo destacado al itinerario: Manuel Fernández Álvarez, Felipe II y su tiempo, Madrid, Espasa, 1998, pp. 695-711. Henry Kamen, Felipe de España, Madrid, Siglo XXI, 1998, pp. 34-49. Geoffrey Parker, Felipe II. La biografia definitiva, Barcelona, Planeta, 2010, pp. 96-107. Desde la ladera de la crítica de arte los textos de Roy Strong, Arte y poder. Fiestas del Renacimiento. 1450-1650, Madrid, Alianza Forma, 1988, pp. 96-102, y Fernando Checa Cremades, Carlos V y la imagen del héroe en el Renacimiento, Madrid, Taurus, 1987, pp. 221-232, son dos clásicos a los que conviene añadir ahora, más centrado en el estudio de las armaduras, Braden Frieder, Chivalry and the Perfect Prince. Tournaments, Art and Armor at the Spanish Habsburg Court, Kirksville (MO), Truman State University Press, 2008, cap. 4. Conviene así mismo tener presentes los trabajos introductorios de Carlos José Hernando Sánchez, José Luis Gonzalo Sánchez-Molero, José Martínez Millán y Santiago Fernández Conti, Antonio Álvarez-Ossorio Alvariño, y Fernando Checa que acompañan a la edición de Paloma Cuenca de la crónica de Juan Cristóbal Calvete de Estrella, El felicíssimo viaje del muy alto y muy poderoso Príncipe don Phelippe, Madrid, Sociedad Estatal para la conmemoración de los centenarios de Felipe II y Carlos V, 2001. Sylvène Édouard, L'Empire imaginaire de Philippe II. Pouvoir des images et discours du pouvoir sous les Habsbourg d'Espagne au XVIe siècle, París, Honoré Champion, 2005 ofrece en su cap. I «Le chevalier aventurero», una interesante revisión de la simbología de los montajes festivos del viaje. En lo tocante a las implicaciones dramáticas siguen sin ser superados el estudio y la antología de Teresa Ferrer Valls, Orígenes y desarrollo de la práctica escénica cortesana: de la época del emperador a la de Felipe III, Londres, Támesis Books, 1991 y Nobleza
} 
cionan los asuntos recurrentes que irán jalonando los montajes de las arquitecturas efímeras o de los tableaux vivants. Éstos se centran en buena medida sobre la transmisión de las responsabilidades de gobierno de padres a hijos². Un espectáculo caballeresco se sumará a los festejos pensados para exaltar la figura del príncipe llamado a emular, y aun a superar, las empresas paternas. Lo que es un extendidísimo motivo de notable rendimiento narrativo (la espada desenclavada del padrón por el heredero de la recta línea sucesoria ${ }^{3}$ ) se constituye en episodio culminante del torneo de invención ${ }^{4}$ que en agosto de 1549 se organizó en la residencia real de María de Hungría a mayor honra del príncipe Felipe. Daniel Devoto desveló magistralmente la perfecta conjunción de política y folclore en este episodio previo a la liberación del Castillo Tenebroso ${ }^{5}$. Intentaré en este trabajo centrarme en el papel que la escenografía, la tramoya y los atisbos de actuación de los participantes tienen en el trasvase de los motivos folclóricos al campo espectacular de la justa.

La prueba ${ }^{6}$ quedó instituida días antes en el palacio de Bruselas recurrien-

y espectáculo teatral (1535-1622): estudios y documentos, Valencia, UNED, 1993. Puede consultarse también Lilia Ferrario de Orduna, «Sobre El felicísimo viaje de Calvete de Estrella: una poética de las entradas reales. Ficción y realidad», Anuario de Letras, 35 (1997), pp. 461-487.

${ }^{2}$ Silvio Leydi resalta el hecho de que el cargo de emperador no sea hereditario sino electivo, pues esa circunstancia marca el tipo de propaganda que debe difundirse. Por ello la ayuda de Hércules a Atlas para sostener el globo terráqueo es el motivo recurrente del felicísimo viaje a su paso por Milán, cuando, de hecho, no se había empleado con esa frecuencia e intencionalidad nunca antes (si acaso en Nápoles en 1535, aunque cada uno con su globo y sus columnas respectivamente). Sub Umbra Imperialis Aquilae. Immagini del potere e consenso politico nella Milano di Carlo V, Florencia, Leo S. Olschki Editore, 1999, pp. 14-15 y 140-141. Marcel Lageirse trata el programa iconográfico de la translatio dignitatis en «La Joyeuse entrée du Prince Philippe à Gand en 1549», Jean Jacquot, Les Fêtes de la Renaissance. II : Fêtes et cérémonies au temps de Charles V, París, CNRS, 1975, pp. 297-306. El volumen recoge una serie de trabajos de especial interés para la interpretación del viaje. Así mismo pueden consultarse con provecho: Jac Geurts, «Myth, History and Image in the Low Countries in the Sixteenth Century», en Laura Cruz \& Willem Frijhoff, (eds.), Myth in History, History in Myth, Leiden, Brill, 2009, pp. 53-85. Yona Pinson, «Imperial Ideology in the Triumphal Entry into Lille of Charles V and the Crown Prince (1549)», Assaph. Studies in Art History, 6 (2001), 205-232. Y Emily Peters, «1549. Knight's game at Binche. Constructing Philip II's Ideal. Identity in a Ritual of Honor», en R. Falkenburg (ed.), Court, state and city ceremonies, Zwolle, Waanders, 1999, pp. 11-36.

${ }^{3}$ D1654.4.1. Sword can be moved only by right persons; H31.1. Recognition by unique ability to dislodge sword from stone or tree. (Stith Thompson, Motif-Index of Folk-Literature: A Classification of Narrative Elements in Folktales, Ballads, Myths, Fables, Mediaeval Romances, Exempla, Fabliau, JestBooks, and Local Legends, Bloomington, Indiana University Press, 6 vols.).

${ }^{4}$ Adopto la designación propuesta por Pedro M. Cátedra en su espléndido trabajo: «Jardín de Amor». Torneo de invención del siglo XVI ahora nuevamente publicado con motivo del IV Centenario del "Quijote» (1605-2005), Salamanca, Seminario de Estudios Medievales y Renacentistas \& Mundus Libri, 2005-06.

${ }^{5} \mathrm{El}$ artículo apareció en francés en la importante recopilación de Jacquot citada en nota 2 y fue recogido en español en «Política y folklore en el Castillo Tenebroso», Textos y contextos: estudios sobre la tradición, Madrid, Gredos, 1974, pp. 202-241. El autor, aun admitiendo que puede haber influencias librescas directas, resalta el carácter folclórico de los detalles.

${ }^{6} \mathrm{H} 1313$. Quest for person who can withdraw sword. En el Primaleón, 2, 213, 526 la búsqueda va 
do ya de entrada a un resorte narrativo que comparten libros de caballerías y saraos cortesanos: un caballero roto ${ }^{7}$ entra en la sala en la que está a punto de concluir el banquete previo a una entrega de premios ganados en una justa y pide permiso al Emperador para fijar en la puerta del palacio la convocatoria de un torneo ${ }^{8}$. Previamente le había dado la carta que desarrolla la anécdota de fuerte contenido literario. Es una variante del consabido «alzadas las tablas $»^{9}$, registrado en tantas relaciones de fiestas e igualmente ligado al final de muchos banquetes en narraciones caballerescas. En unas y otras suele introducir un fantasioso espectáculo o la invitación a una aventura o desafío ${ }^{10}$.

No termina ahí la contaminación entre la crónica y la ficción, pues afecta también al modo de organizar el relato; el entrelazamiento, que hunde sus raíces en la búsqueda de solución al reto de la ordenación cronológica, aflora y nos recuerda un motivo metanarrativo ${ }^{11}$ de los libros de caballerías: Ido el caballero con el permiso para anunciar el torneo, «puso el cartel a la puerta del palacio, del qual y de la carta que al Emperador presentó diremos en su

ligada a un torneo, según apunta Ana Carmen Bueno Serrano, Índice y estudio de motivos en los libros de caballerías castellanos (1508-1516), Tesis doctoral dirigida por Juan Manuel Cacho Blecua, 4 vols., Zaragoza, Departamento de Filología Española (Literaturas Española e Hispánicas) de la Universidad de Zaragoza, 2007. En lo sucesivo, cito su índice con las iniciales BS y omito la localización de los pasajes.

${ }^{7}$ En el ámbito cronístico cabe recordar, como mínimo, la entrada de la compañía de pajes en la sala del castillo del Condestable de Jaén en 1461, «la qual venía destroçada e vençida de gente enemiga» (p. 51 de la edición de Juan de Mata Carriazo, Hechos del Condestable Don Miguel Lucas de Iranzo. Crónica del siglo XV, Madrid, Espasa-Calpe, 1940).

${ }^{8}$ BS. Embajada de caballero para desafío a combate por carta; BS. Embajada de caballero para desafío a lucha a la corte de un emperador, las mesas alzadas.

9 "«'Alzadas las mesas' es un motivo - más bien, la parte de un motivo, una indicación temporal- porque concurre en varios textos caballerescos, tiene un significado temporal propio, fija el cronotopo de la acción, y sirve de indicio ya que, en ciertas ocasiones, el final de la comida trae asociado el comienzo de una aventura (la entrada de una doncella o dueña solicitando ayuda, la aparición de un caballero desafiando al héroe o la llegada intempestiva de una fantasía mágica previamente dispuesta). Tiene un significado autónomo, si bien en el contexto su relevancia queda subordinada a otros que funcionan como desencadenantes o generadores de la acción y en relación con esta jerarquía interna o grado de pertinencia sirve de indicio, detonante o punto de partida. La categoría del motivo no se establece por el enunciado en sí, sino por la función narrativa que desempeña la unidad en el libro de caballerías». Ana C. Bueno Serrano, ob.cit., pp. 183-185. Conviene no olvidar el motivo caballeresco ligado a la introducción del torneo: BS. Celebración de festejos antes de un combate.

${ }^{10}$ Quiero recordar la sagacidad de Martín de Riquer a la hora de interpretar el episodio de Arturo en Constantinopla del libro de Martorell (caps. 86-92) como un entremés, echando mano entre otras cosas de su indudable relación con un espectáculo de sobremesa. Martí de Riquer, Aproximació al Tirant, Barcelona, Quaderns Crema, 1990, pp. 150-156. Y para una opinión diferente: Rafael Alemany Ferrer, «L'episodi tirantià d'Artús és neccesàriament un entremés?», en Actas del IX Congreso Internacional de la Asociación Hispánica de Literatura Medieval (A Coruña, 18-22 de septiembre de 2001), eds. Carmen Parrilla y Mercedes Pampín, La Coruña, Universidade da Coruña, Toxosoutos, 2005, 1, pp. 251-266.

${ }^{11}$ Ana C. Bueno Serrano, ob.cit., pp. 191-217. Véase así mismo: Juan Manuel Cacho Blecua, «El entrelazamiento en el Amadís y en las Sergas de Esplandián», en Studia in honorem prof. M. de Riquer, Barcelona, Quaderns Crema, 1986, 1, pp. 235-271. 
lugar y tiempo» ${ }^{12}$. El recurso pone en juego el suspenso, evita repeticiones y cohesiona el resultado final ${ }^{13}$. Días después cuando la comitiva imperial se encuentra en las salas del palacio de Binche, la carta se traslada punto por punto $^{14}$. Recojo a continuación sus párrafos más importantes para facilitar la comprensión del trabajo:

Desde toda la antigüedad ha sido lícito y permitido, Cesárea magestad, a todos los cavalleros y nobles personas que por ganar honrra exercitando las armas han querido buscar aventuras estrañas ${ }^{15}$, de ir libre y francamente por todos los reinos, tierras y señoríos, sin que jamás se les haya dado estorvo ni embargo alguno si no ha sido de los enemigos de cavallería, salteadores de caminos y personas que han reputado a virtud exercitar toda violencia y crueldad, prefiriendo su vicio y malignidad a qualquier honestidad y derecha ygualdad. De suerte que muchos, sintiendo la debilidad y flaqueza de sus fuerças y personas en poder llevar al cabo sus designios con el exercicio y desteridad de las armas, han recurrido a hechizos y artes diabólicas y por invocaciones abominables, ayudándose de ciertos encantamientos con los cuales han effetuado infinitos males, es a saber: muertes, homicidios, hurtos, robos y finalmente detenciones, encarcelamientos y cautiverios de muchas nobles personas, tanto que algunas vezes estos ultrajes inhumanos han podido más que la voluntad y fuerças de los que desseavan remediarlo, aunque en fin a la larga la salida d'ello ha sucedido siempre en confusión y perdición de las tales personas injustas, recibiendo las penas condignas a sus méritos, como se puede leer en las antiguas y más auténticas historias.

Parece ser, señor, que desde algunos años a esta parte, aviéndose celebrado el nombre de vuestra imperial magestad y bolado por el universo mundo, según dicho es, se ha venido a recoger en esta su Gallia Bélgica junto a la villa de

${ }^{12}$ Ligada al motivo queda la fórmula: «Muy maravillado quedó el Principe y todos aquellos señores y cavalleros de lo que el andante cavallero avía dicho, y muy desseosos de hallarse ya en Bins por provarse en aquella estraña aventura que avía contado». Sobre este asunto remito a lo recordado por Juan Manuel Cacho Blecua, «Introducción al estudio de los motivos en los libros de caballerías: la memoria de Román Ramírez», en Libros de caballerías (De «Amadís» al «Quijote»). Poética, lectura, representación e identidad, eds. Eva Belén Carro Carbajal, Laura Puerto Moro, María Sánchez Pérez, Salamanca, Seminario de Estudios Medievales y Renacentistas - Sociedad de Estudios Medievales y Renacentistas, 2002, pp. 27-57. En la p. 38 se plantea el margen de cercanía a las fórmulas estilísticas tan características de la épica y también detectables en los libros de caballerías. Sin ese nivel formulístico estereotipado no hubiese sido posible la improvisación de Román Ramírez.

${ }^{13}$ Devoto ya destacó la destreza de Calvete a la hora de jugar con la curiosidad del lector y su virtuosidad para presentar lo fatal y previsible en el momento justo (art. cit., p. 211).

${ }^{14}$ En Calvete se dice que se lee en Bruselas y a modo de intermedio al final de la cena y antes de la entrega de premios del torneo. Según el texto alemán estudiado por Emily Peters, fue el emperador quien la leyó en voz alta (art. cit., p. 13).

${ }^{15} \mathrm{H} 1220$. Quests voluntarily undertaken; H 1221. Quest for adventure; H1223. Quest to undertake feats of valor. 
Bins, sobre la vieja y antiquísima calçada de Brunheault, un encantador enemigo de la cavallería, de virtud y de toda igualdad llamado Norabroch, el qual por sus artes y hechizos ha cometido y perpetuado inestimables males, buscando todas maneras para atraer y detener en cruel cativerio, no solamente los cavalleros y nobles d'esta provincia de vuestra Magestad, mas aun de las tierras circunvecinas y forasteras, con apariencia que ay que acometerá y perpetrará otros muchos y mayores males si Dios con su infinita gloria, con la esperança que se tiene de vuestra magestad, no lo provee y remedia presto. Tiene su morada el dicho Norabroch en un castillo de tal suerte encantado que continuamente está embuelto y cubierto de una tan espessa y escura nuve, que en ninguna manera se dexa acercar ni menos reconocer y por esto se llama Tenebroso $^{16}$, salvo que por conjeturas se puede poco más o menos atinar el lugar de su sitio a causa de la Isla Venturosa, de la Torre Peligrosa y del Passo Fortunado, donde son forçados provarse todos los cavalleros errantes ${ }^{17} \mathrm{y}$ atraídos allí por encantamientos con las condiciones y pactos que abaxo serán declaradas. Mas hase de entender principalmente que como la providencia sea en todos los actos y hechos humanos la más necessaria, la Reina Fadada, princesa humana y amadora del bien y tranquilidad de todas las nobles personas, con su sciencia y experiencia de lo porvenir ${ }^{18}$, viendo quán perjudicial y dañoso era el nacimiento del dicho Norabroch, proveyó e instituyó en la dicha Ysla Venturosa una peña harto alta y en la cumbre d'ella un padrón en que está hincada una espada de tanta efficacia y virtud ${ }^{19}$ como se puede interpretar por ciertas proffecías y escritos de lengua tan antigua que apenas se dexan entender agora ${ }^{20}$ en dos altas colunas edificadas en la dicha isla; es a saber:

QUE EL CAVALLERO QUE SACARE FUERA LA ESPADA DEL DICHO PADRÓN DARÁ TAMBIÉN FIN A LA AVENTURA Y DESHARÁ LOS ENCANTAMIENTOS Y LIBRARÁ LOS PRISIONEROS DEL CRUEL CATIVERIO EN QUE ESTÁN Y FINALMENTE ECHARÁ EN EL ABISMO AL DICHO CASTILLO TENEBROSO ${ }^{21}$ Y DEMÁS D'ESTO ALCANÇARÁ UNA INFINIDAD DE OTRAS MUCHAS BUENAS AVENTURAS, AUNQUE AQUÍ NO SE DECLARAN, QUE LE SON PROMETIDAS Y DESTINADAS

\footnotetext{
${ }^{16} \mathrm{BS}$. Invisibilidad mágica del puente y la torre de un castillo por encantamiento de maga.

${ }^{17}$ BS. Desafío a combate de caballeros a caballeros en isla; BS. Desafío a combate de caballeros a caballeros en puente; BS. Mantenimiento de la costumbre de combate para el paso por un puente guardado por los caballeros de un castillo; BS. Mantenimiento de la costumbre de combatir contra el mago encantador, caballero y señor de un castillo.

${ }^{18}$ D1711.5. Fairy as magician D1712.0.1. Astrologer-magician. Queda cercano del motivo caballeresco: BS. Conocimientos nigrománticos aprendidos por maga.

${ }^{19} \mathrm{BS}$. Obtención de una espada mágica extrayéndola de un padrón que solo puede ser movida por un caballero.

${ }^{20} \mathrm{BS}$. Escritura de una profecía enigmática por estar escrita en letras que nadie ha podido descifrar.

${ }^{21}$ BS. Liberación de los prisioneros de un castillo; BS. Desencantamiento permanente de un castillo encantado por caballero; BS. Incendio del castillo y puente de un caballero como castigo.
} 
En lo qual muchos cavalleros han hecho su dever y se han puesto a la prueva de la dicha espada; mas todo ha sido en balde ca la mayor parte d'ellos ha quedado en manos del encantador y bien pocos han llegado hasta allí que hayan podido bolverse sino confusos; de manera que la dicha espada queda todavía en su ser sin que hasta agora alguno haya avido la victoria d'ella ${ }^{22}$. Assí que sabiendo por presencia la dicha Reyna Fadada de qué inhumanidad y tiranía devía ser acompañado el dicho Norabroch, deleitándose más que nunca hombre hizo en la detención y cativerios de todos los cavalleros, menos comportable que la muerte cruel, para refrenar su maligna voluntad, después de aver constituido la dicha Isla Venturosa, la peña, el padrón, la espada y Torre Peligrosa y assimismo el Passo Fortunado, según arriba lo puede aver entendido vuestra Magestad, insitituyó y estableció que tres cavalleros, cada uno d'ellos con ayuda y assistencia de dos o tres, harían allí su residencia en guarda d'estos tres passos; es a saber: uno al Passo Fortunado, que es el primero, donde ay una puente sobre un muy profundo río cercada de una fortíssima barrera. El cavallero que guarda este primero passo se llama del Griphón Colorado. En la Torre Peligrosa, que es el segundo passo ay otro Cavallero del Águila Negra. Y en el tercero passo, que es más adelante de la dicha torre peligrosa, delante de la Isla Venturosa, está el tercer cavallero, que se llama el Cavallero del León de Oro. Hora, por todos los cavalleros errantes o atraídos por los encantamientos del dicho Norabroch que quieran proceder a la prueva de la dicha espada son las condiciones y pactos de la manera que se siguen:

Primeramente, que como el cavallero aventurero viene al lugar delante de la barrera, la qual halla cercada, deve tañer una bozina de marfil que cuelga del padrón que está cabe la dicha barrera ${ }^{23}$, a cuyo son asoma un enano fuera de un torrejón junto a la barrera. El qual dize que será luego recibido y va avisar de su venida al cavallero mantenedor. En este medio el cavallero del Griphón aviendo ya oído el son de la bozina, sube a cavallo y se pone en el lugar al combate. Después manda al portero que abra la barrera y allí es recibido. Y si el cavallero aventurero haze mejor su dever que el del Griphón, es a saber: si rompe mejor su lança, si da mejor encuentro o se ha mejor en las tres carreras que el mantenedor, pueda fácilmente passar adelante del primer passo. Pero si el Cavallero del Griphón haze su dever mejor que el aventurero, es obligado entonces el aventurero de apearse luego en el mismo instante y rendirse por prisionero, llevándolo a Norabroch al castillo Tenebroso y porque el dicho castillo es invisible el cavallero prisionero será guiado de gentileshombres para este effeto ordenados para ello ${ }^{24} .(\ldots)$

${ }^{22} \mathrm{H} 125.1$. Identification by sword; H1313. Quest for person who can withdraw sword. BS. Obtención de una espada mágica extrayéndola de un padrón que solo puede ser movida por un caballero.

${ }^{23} \mathrm{BS}$. Aviso de la llegada de un caballero por sonido de instrumento.

${ }^{24} \mathrm{BS}$. Traslado de prisioneros a un castillo; BS. Cautiverio como castigo por derrota en un combate. 
Aviendo el cavallero aventurero ganado el segundo passo, se le abre la puerta de la Torre Peligrosa y allí se deve apear para passar adelante, donde entra el tercer passo, en el qual es recebido del cavallero del León de Oro a tantos golpes de espada (...). Si el aventurero haze mejor su dever que el mantenedor serále permitido de ser recibido en la barca y passar de la otra parte del agua a la Isla Venturosa.

Llegado el aventurero a este passo deve dezir y declarar su nombre y sobrenombre sin dissimulación alguna ${ }^{25}$ para que sea escrito en la memoria de los estremados y valerosos, la qual memoria tiene cargo de hazer el capitán de la barca, que los passa a la Isla Venturosa ${ }^{26}$, establecido para esto de la Reina Fadada, adonde se guardan otros muchos secretos y después deve el dicho cavallero subir a la peña que está en la dicha Isla Venturosa y llegar hasta el padrón que está sobre ella y allí se provará si podrá de un solo tirón arrancar una espada que está hincada en el padrón ${ }^{27}$, acompañado para este effeto del capitán de la barca y de su compañía. (...)

Siendo el cavallero aventurero tan dichoso, lo qual plegua a dios permitir por su santa gracia, que saque fuera la dicha espada, deve seguir punto por punto la instrucción que el dicho capitán de la barca le dará. La qual instrucción, según dizen se ha de sacar de la prophecía escrita en dos colunas ${ }^{28}$ que están en la dicha isla para que seguramente pueda passar al Castillo Tenebroso, antes que se desaparesca de la nuve que le encubre, porque de otra manera le podría redundar mucho mal y inconviniente dello. (...)

Todos los quales pactos, condiciones y puntos susodichos nos han sido declarados de poco acá por cierto cavallero que en ello se avía provado, affirmado por la orden de cavallería averlos sacado de los padrones, colunas, obeliscos y pilares diversamente instructos y ordenados en los dichos tres passos, donde estavan escritos en antiquíssima lengua ${ }^{29}$, los quales embiamos a vuestra magestad con la mayor humildad y reverencia para que sea servido hazerlos publicar y divulgar a todos los cavalleros y nobles de su corte y otros a fin que estando vuestra Magestad en Bins quieran provar esta aventura porque muchos o casi todos aviendo navegado todos los mares y frequentado la Asia, África, Indias y los estremos del mundo, han provado muchas y muy loables esperiencias, acabando diversas y estrañas aventuras dignas de admiración, assí se espera que entre tan gran multitud de todas las naciones de que vuestra Magestad es

\footnotetext{
${ }^{25}$ BS. Identificación de un caballero por información directa como condición de justa.

${ }^{26} \mathrm{BS}$. Viaje de caballeros en barca mágica construida por mago.

${ }^{27} \mathrm{BS}$. Obtención de una espada mágica extrayéndola de un padrón que solo puede ser movida por un caballero.

${ }^{28}$ BS. Profecía escrita encontrada casualmente en una construcción.

${ }^{29} \mathrm{BS}$. Hallazgo de un manuscrito en circunstancias extraordinarias.
} 
servido, honrado, temido y armado, avrá algún dichoso y venturoso que podrá llegar al cabo d'esta aventura y encantamiento tan estraño. (...)

Humilísimos y obedientíssimos servidores. Los cavalleros errantes de su Gallia Bélgica ${ }^{30}$.

El texto, que desarrolla las bases literarias de la invención elegida como núcleo del torneo, es un compendio de motivos, casi todos ellos habituales en las ficciones caballerescas. Como queda reflejado en las notas anteriores, los repertorios de Stith Thompson y Ana C. Bueno Serrano registran buena parte de los motivos ligados a este arranque imaginativo de la prueba. A nadie familiarizado con esta materia o con los relatos tradicionales le pueden extrañar las malas artes de un encantador que se ha confabulado contra los andantes, atrayéndolos hacia sus dominios y apresándolos en un castillo recóndito y escondido entre brumas. La lógica narrativa del folclore exige una polarización entre las fuerzas del Bien y del $\mathrm{Mal}^{31} \mathrm{y}$, en consecuencia, al mago enemigo se opone la figura de la maga protectora, encarnada en el texto por la Reina Fadada. Sus saberes le llevan a prever las consecuencias de las acciones de Norabroch y a actuar para contrarrestarlas. Como hazaña previa al asalto final instituye en la Isla Venturosa la prueba de la espada desenclavada tan prodigada en formulaciones legendarias y sobre la que después convendrá decir algo al respecto de su adecuación a las circunstancias históricas. Detengámonos por ahora en la disposición del terreno para ver cómo la adaptación a las particularidades del torneo en el espacio al aire libre de la residencia de María de Hungría se pliega a las exigencias de los enclaves tópicos de la aventura. Sabremos así qué nos dicen la escenografía, la tramoya y la actuación de los participantes en sus modos de trasvasar las marcas propias de la materia caballeresca al espectáculo. Porque la poética del género no solo se difunde en los escritos, también el espacio festivo es un ámbito que contribuye a dar a conocer sus constantes narrativas a un amplio público. Piénsese en que la frase «más bravas que las fiestas de Bains» se hizo proverbial para referirse a lo fastuoso de las ceremonias ${ }^{32}$.

\footnotetext{
${ }^{30}$ La carta ocupa las pp. 325-330 de la edición citada en nota 1. Doy a partir de ahora el $\mathrm{n}^{\mathrm{o}}$ de la página entre paréntesis. He tenido presentes la edición original de Amberes, Martín Nucio, 1542 y la de Madrid, Sociedad de Bibliófilos Españoles, 1930.

${ }^{31}$ Axel Olrik, «Epic Laws of Folk Narrative», en Alan Dundes (ed.), The Study of Folklore, New Jersey, Prentice- Hall, 1965, pp. 129-141.

${ }^{32}$ Devoto, art. cit., p. 204, n. 4.
} 
El lugar elegido, el palacio de recreo de la hermana de Carlos V a las afueras de Binche, tiene la virtud de proporcionar algunos de los elementos básicos ligados al espacio en los libros de caballerías: el castillo, apoyado en grandes y muy fuertes murallas, con sus torres y la variedad de ventanas que permiten la estratificación de los espectadores por rango; el camino, que aquí se plasma en dos vías diferentes, la que lleva a los campos pensados para el enfrentamiento y la senda secreta que conduce a los derrotados al Castillo Tenebroso y que muy bien podría recordar tantos senderos relacionados con la visita al Otro Mundo ${ }^{33}$. De hecho, la disposición del terreno, que se intuye en la crónica como una combinación de colinas, cursos de agua, claros de bosque y huertos o jardines, permite conjugar los espacios de la aventura con los requerimientos del torneo ofrecido a la mirada de los espectadores, tanto nobles como plebeyos:

Estava cercada la calçada de una fortíssima barrera por entrambas partes, casi ciento y cinquenta passos en largo, que era el espacio necessario para correr

(...) porque aquella real casa está casi edificada sobre la muralla y toma algunas torres d'ellas, las quales son grandes y muy fuertes, y debaxo d'ellas va la antiquíssima calçada de Brunheault, entre la cerca y unos collados que agora son huertas. (330)

No se puede pensar la gente que de los collados de una parte y de otra corrían; saltavan las barreras y muchos sobre los árboles se subían a mirar qué sucesso tendría, y lo mismo hazían los que estavan por la cerca, miradores y torres del palacio real, y de las ventanas el Emperador y Reynas y las damas ${ }^{34}$ (341).

Por otra parte, en la preparación del montaje festivo destaca un mecanismo que nos habla a las claras de las deudas de este tipo de libros con el mundo de las leyendas y el folclore. Para llegar al final previsto en la carta, la liberación de los presos en el Castillo Tenebroso, la disposición del torneo se pliega a una regla básica de la narrativa tradicional: la ley del tres ${ }^{35}$. El caballero debe vencer al mantenedor del Passo Fortunado para luego probar suerte con el de la Torre Peligrosa y por último cruzar a la Isla Venturosa y ensayar la prueba de la espada. Es ésta el elemento central visible del montaje escenográfico al aire libre. Y resalto su visibilidad porque, como se verá, su colocación

${ }^{33}$ F95. Path to lower world. F151.1. Perilous path to otherworld.

${ }^{34} \mathrm{BS}$. Observación de torneos desde miradores por reyes, dueñas y doncellas; BS. Observación de torneos desde miradores por padre.

${ }^{35}$ Olrik, art. cit. 
en lugar destacado por la altura permite el disfrute y observación de la escena desde prácticamente todos los ángulos. Ahora bien, para llegar allí los participantes han de superar las dos pruebas anteriores. La primera fase del torneo implica afrontar el Passo Fortunado, «donde ay una puente sobre un muy profundo río cercada de una fortíssima barrera» que guarda el Caballero del Grifón, recogido en su espera en una tienda armada al cabo de la carrera. Puente, barrera que impide el paso y tienda son los escuetos elementos que, sin embargo tienen un profundo potencial evocador al permitir enlazar las circunstancias del torneo con infinidad de aventuras caballerescas ${ }^{36}$.

Al llegar al espacio de la Torre Peligrosa, el mantenedor era avisado de la llegada de los aventureros desde «el torrejón con una ventana donde el enano se ponía. Estava el torrejón arrimado a unas puertas del altor de la barrera que cerravan la carrera». Prevenido el mantenedor, dos villanos de hacha y capellina abrían las puertas. El espacio que se ofrece a sus ojos cuenta con una columna y capitel que sostenían el escudo de armas del Caballero del Águila Negra, más una bocina y un letrero amenazante. Pocos son los elementos escenográficos, pero todos ellos tienen así mismo un fuerte poder asociativo. El torrejón se contamina con los castillos de la mala costumbre ${ }^{37}$ por la intervención de aviesos personajes: el enano que da la alerta ${ }^{38}$ y los villanos. El letrero que advierte de los peligros y la insistencia en las puertas que se abren y cierran inexorablemente ${ }^{39}$ contribuyen a resaltar la importancia de los umbrales de la aventura: «Que el cavallero andante que de un golpe de lança y siete de espada no venciesse al cavallero del Águila Negra iría preso al castillo y si lo venciesse podría passar libremente al tercer combate» (331).

Llegaría tras la victoria el momento de desvelar el nombre del caballero tan esperado. Como establecía la carta, ahora tiene ocasión de descubrirse y de registrarse en el libro secreto custodiado por el capitán de la barca. Se conjugan así de manera óptima, con un simple recurso de atrezo, el motivo caballeresco del final de la ocultación del nombre ${ }^{40}$ y la práctica minuciosa del registro notarial de los torneos. ${ }^{41}$

${ }^{36}$ BS. Desafío a combate de caballeros a caballeros en puente; BS. Mantenimiento de la costumbre de combate para el paso por un puente guardado por los caballeros de un castillo.

${ }^{37} \mathrm{BS}$. Victoria de un caballero contra todos los que mantienen la costumbre de un castillo. Véase: Anna Bognolo, «Dal mito alla corte. I castelli della malvagia usanza (Studio di un tipo di avventura arturiana e della sua trasformazione nel Amadís de Gaula)», Annali della Facoltà di Lettere e Filosofia dell'Università degli Studi della Basilicata, 4 (1992-1993), pp. 105-125.

${ }^{38}$ F451.5.1.7. Dwarfs serve mortals; D1222. Magic horn (musical).

${ }^{39} \mathrm{BS}$. Captura de caballero por cierre de puertas de un castillo por villanos

${ }^{40} \mathrm{BS}$. Identificación de un caballero por información directa como condición de justa.

${ }^{41}$ Son básicas las páginas escritas por Pedro M. ${ }^{\mathrm{a}}$ Cátedra sobre este asunto en el estudio introductorio al Jardin de amor citado en nota 4. 
Como se ha apuntado más arriba, y en paralelo a su importancia en la trama, el lugar más destacado es la Isla Venturosa. Fabricada sobre un curso de agua que la rodea ${ }^{42}$, requiere la presencia de un elemento de tramoya que traduce no sólo la intervención de animales mágicos en las narraciones caballerescas, (muy concretamente la sierpe o dragón), sino las barcas misteriosas de los immram $^{43}$. Sin olvidar que para los lectores del Amadís es inevitable el recuerdo de la Fusta de la Gran Serpiente de Urganda la Desconocida, personaje que en su función de maga protectora pudo haber inspirado la figura de la Reina Fadada y quizás planear sobre la labor mediadora de la anfitriona de Binche, María de Hungría ${ }^{44}$ :

Estava aquel campo donde el combate de pie se hazía ribera de un profundo río que a la Isla Venturosa cercava, el qual se passava con una estraña barca hecha a forma de dragón pintado de colorado y oro con una cámara en la popa ricamente adereçada con sus remos de colorado y oro. Remávanla dos barqueros estraños en el hábito y gesto, con ropas hasta en pie de raso carmesí a la antigua. (332)

Sus no menos misteriosos remeros recuerdan otros tantos personajes enigmáticos, en buena medida silentes, de no pocas leyendas y relatos, también entre ellos los caballerescos ${ }^{45}$. Su misión es trasladar a los participantes a la otra orilla. Llegados a ella a la altura de dos obeliscos que en la Litera della gloriosa et trionfante entrada del Principe Serenissimo di Spagna in Bins, citta di Fiandra se relacionan con las columnas del Plus Vltra carolino ${ }^{46}$, la disposición del terreno resalta el lugar en el que tendrá lugar la prueba definitiva de la espada, pues para llegar a ella hay que abordar una subida algo áspera y difficultosa como gradas. Según apuntara Juan Manuel Cacho para la aventura de la Cámara Defendida en el Amadis, modelo que pudo haber

\footnotetext{
${ }^{42}$ Es detalle que apunta el firmante de la Litera della gloriosa et trionfante entrada del Principe Serenissimo di Spagna in Bins, citta di Fiandra: «nel quale atto si abbassò subito un ponte levatoio del isola fabbricata a mano» (Charles Ruelens, Le siège et les fêtes de Binche (1543-1549). Deux documents publiés avec traduction et notes par ...., conservateur des manuscrits de la Bibliothèque Royale de Belgique, Mons, Dequesne-Masquillier, 1878, pp. 66-123. (El texto en p. 90).

${ }^{43} \mathrm{D} 2120$. Magic transportation; D2121. Magic journey; F911.3.2. Winged serpent as boat: passengers within.

${ }^{44}$ «...ne riportò la spada incantata donatagli dalla Regina di valore di quindici mille scudi» (Litera..., cit. p. 90).

${ }^{45}$ Véase para un ejemplo de empleo en los libros de caballerías mi trabajo: Alberto del Río, «El desvío del paradigma de género en el Claribalte, novela de caballerías de Gonzalo Fernández de Oviedo», Salastano. De interpretación textual, Huesca, Colegio Universitario, 1985, pp. 99-119.

${ }^{46}$ «Vincendo passava in una ornatissima barca certo rio, su l'argine del quale trovava due colonne in similitudine di quelle d'Hercole...» (Litera cit., p. 80).
} 
inspirado este tramo del montaje festivo ${ }^{47}$, la organización del espacio es claramente simbólica en cuanto busca traducir lo arduo del reto ${ }^{48}$. Sin olvidar que la elección de un promontorio facilita la visión de la hazaña a los espectadores que se agolpan en torno a los diversos lugares del torneo ${ }^{49}$. Así mismo hay en algún párrafo de la crónica indicios de su excepcionalidad como lugar de difícil acceso y, en consecuencia, poco hollado:

Y en lo alto en medio della parecía un padrón de jaspe cercado de muy crecida y fresca yerva que en torno d'él avía nacido, que mostrava y era señal de aver pocos cavalleros que allí uviesen llegado ${ }^{50}$. (332)

Desenclavada la espada del padrón, renovado y nacido el héroe a su nueva identidad, le queda salir del espacio aislado por el agua para retornar triunfador a una simbólica tierra firme en donde podrá culminar su tarea salvífica: la liberación de los caballeros presos en el castillo de Norabroch. La elección del lugar para su enclave resalta la función de umbral de regreso del curso de agua y destaca el significado central del rito de paso asociado a la extracción del arma, así como la situación marginal del castillo en los márgenes del Bien ahora ensanchados por el príncipe:

Estava fundado con gran arte entre el septentrión y occidente de la otra parte del un braço del río que con el otro, que se passava con la estraña barca, hazía la Ysla Venturosa. Avía sobre aquel braço del río, que por allí iva muy angosto y ancho, una puente desde la isla hasta la ribera donde estava el castillo. La qual por la fuerça del encantamiento no se vía. Era aquel Castillo Tenebroso

\footnotetext{
${ }^{47}$ Coincide en significativos aspectos la disposición de la prueba central de la Isla Venturosa con la hazaña fallida de Amadís y acabada por Esplandián: las gradas que llevan a lo alto de la peña en la que se encuentra la cámara con la espada, las inscripciones con el mensaje, la reserva de la aventura para el hijo del héroe: «En vano se trabajará el cavallero que esta espada de aquí quisiere sacar por valentía ni fuerça que en sí aya, sino es aquel que las letras de la imajen figuradas en la tabla que ante sus pechos tiene señala, y que las siete letras de su pecho encendidas como fuego con éstas juntará. Para éste se ha guardado por aquella que con su gran sabiduría alcançó a saber que en su tiempo ni después muchos años vernía otro que igual le fuesse» Garci Rodríguez de Montalvo, Amadís de Gaula, ed. de Juan Manuel Cacho Blecua, Madrid, Cátedra, 1988, II, p. 1.707.

${ }^{48}$ Véanse para la interpretación del episodio las imprescindibles páginas de Juan Manuel Cacho Blecua, Amadís: heroísmo mítico cortesano, Madrid, Cupsa, 1979, pp. 331-341.

${ }^{49}$ «No se puede pensar la gente que de los collados de una parte y de otra corrían; saltavan las barreras y muchos sobre los árboles se subían a mirar qué sucesso tendría, y lo mismo hazían los que estavan por la cerca, miradores y torres del palacio real, y de las ventanas el Emperador y Reynas y las damas» (341).

${ }^{50}$ Es indudable la importancia del ars topiaria en este y otros detalles del acondicionamiento del espacio. Recuérdese: «Entre los collados y calçada iva una senda secreta cerrada de entrambas partes de un verde seto hasta el Castillo Tenebroso, por donde llevavan a los cavalleros vencidos a la prisión del cruel Norabroch» (331). «E da lui condotto à una torre poco distante sopra un masso naturalissimamente lavorato, trovavano la spada incantata» (Litera cit., p. 82).
} 
quadrado, cubierto todo de grandes, anchas y escuras telas de pinturas ondeadas que escuras nubes parecían. (332)

Hay además un detalle que remite a una variante del motivo BS. Obtención de armas y caballo destinadas para un caballero por entrega directa de doncella mensajera de maga. Es una funda preciosa lo que se obtiene de manos del capitán:

Así dijo y presentole una vaina de parte de la Reina Fadada llena de tan hermosas piedras y de tan rico valor que bien parecía mandada labrar por tan valerosa mano y para tal espada, que era la mejor que en el mundo avía, y decendiendo con gran presteza por las gradas de la peña con la espada en la mano y la vayna ceñida, porque assí le convenía ${ }^{51}$, tomó la vía del castillo siguiendo su guía. (342)

El puente invisible que se descubre al caballero encumbrado para facilitar el vado avala la interpretación:

Ya llegavan al cabo de la isla quando súbitamente la nuve se deshizo y pareció una puente sobre el río ${ }^{52}$, que antes no avía parecido, y passando la puente vio luego el castillo que hasta allí havía sido invisible. (342)

El montaje festivo cuenta también con otros elementos que, combinando tramoya, recursos escénicos y mínima actuación de los actores ocasionales, traducen a la perfección la esencia de los motivos básicos del género. Por ejemplo, se insiste en el espacio tétrico asociado a estos castillos de irás y no volverás, primero con el decorado que lo oculta: «Era aquel Castillo Tenebroso quadrado, cubierto todo de grandes, anchas y escuras telas de pinturas ondeadas que escuras nubes parecían» (332). Y luego con una conjunción de ruidos, pólvora, gritos y alaridos de los presos conforme se avanza hacia el desenlace del torneo ${ }^{53}$ :

Grandes eran las mudanças que el cielo hazía; ya estava sereno, ya llovía; oíanse espantosas bozes dentro del castillo (339).

Ya avía passado la barca y llegado al padrón, quando súbitamente el cielo se cubrió de nuves y començó a llover, oyéndose en el Castillo Tenebroso muy temerosas vozes, y en un momento tornó a estar sereno el cielo (340).

${ }^{51}$ D1400.1.4.1. Magic sword conquers enemy; D806. Magic object effective only when exact instructions for its use are followed.

${ }^{52}$ BS. Invisibilidad mágica del puente y la torre de un castillo por encantamiento de maga; D2095. Magic disappearance

${ }^{53} \mathrm{BS}$. Comienzo de una tormenta de granizo y viento por mago. 
Ya el sol era puesto y la noche se acercava; estava cubierto el cielo de muy espessas y escuras nuves, oyéndose en el castillo espantosos alaridos, de donde se tenía por cierto que este era el venturoso cavallero que avía de dar fin a la estraña aventura (341).

Acabado de hazer aquello, el tiempo se rebolvió con grandes truenos y dentro del castillo se oían estraños alaridos, lo qual todo hazía el fiero nigromántico por poner miedo y espanto al cavallero (342).

Por último, los motivos se agolpan en el remate del torneo cuando caen las tramoyas que ocultaban la fortaleza y aparecen elementos simbólicos ligados al final del encantamiento:

Y passando la puente vio luego el castillo que hasta allí havía sido invisible, de la puerta del qual estava cerrada y colgava d'ella una redoma ${ }^{54} \mathrm{y}$ avía delante muchos cavalleros ricamente armados que la entrada defendían, porque sabiendo el cruel Norabroch ${ }^{55}$ que sus artes no le aprovecharían contra el que la rica espada ganasse y que con ella desharía todos sus encantamientos, pensando assí valerse, avía sacado aquellos cavalleros de la cruel prisión donde los tenía metidos, y escogidos los más valientes, y encantándolos con su saber para que con su gran esfuerço y valentía defendiessen la entrada ${ }^{56}(342)$.

Y aquí es cuando las dotes de esgrima fingida, la redoma y los mecanismos de tramoya que derriban las puertas, y hasta el hieratismo impuesto a Claude Bouton, señor de Corbaron $^{57}$, hacen su entrada en el juego dramático:

Le herían con mucha braveza, «como aquellos que estavan fuera de juizio»... y no los había bien tocado quando luego caían en el suelo ${ }^{58}$. Llegado a la puerta, dio un gran golpe en la redoma que estava colgada d'ella con su espada;

\footnotetext{
${ }^{54}$ Devoto recuerda su asociación con el grupo de motivos en torno a la separable soul E.710. external soul.

${ }^{55}$ D1810.0.2. Magic knowledge of magician.

${ }^{56}$ BS. Protección de la puerta de entrada a un castillo por diez caballeros encantados.

${ }^{57}$ Nótese la procedencia del nombre del mago, anagrama del título del caballero borgoñón, ya asociado a Felipe el Hermoso como caballerizo mayor. Puede leerse: Eugene Beauvois, Un agent politique de Charles-Quint: le bourguignon Claude Bouton, seigneur de Corberon. Notice sur sa vie et ses poésies, avec le texte de son Miroir des dames et des pièces justificatives pour la plupart inédites, París, Ernest Leroux, 1882, p. ix, n. 2 y capítulo 6 sobre las fiestas de Binche. Emily Peters, que trabaja con la relación alemana, aporta esa clave en su trabajo, aunque le otorga nacionalidad española (art. cit. pp. 11-36). Son curiosas las variantes recogidas por el Thournier kampff unnd ritterspiel..., Frankfurt, 1550: María de Hungría habría hecho entrar a Norabroc a su servicio, pero el caballero se corrompió por las ciencias ocultas y engañó a la reina ocupando un castillo en las afueras de sus dominios.

${ }^{58}$ D700. Person disenchanted; G303.20.1. Disenchantment by sword; BS. Desencantamiento permanente de caballero encantado por uso de espada mágica.
} 
estava dentro d'ella toda la fuerça y artificio del encantamiento ${ }^{59}$; apenas avían caído las pieças de la redoma quebrada, quando las puertas cayeron y se levantaron los cavalleros como de un sueño adormidos; no se detuvo el gloriosíssimo príncipe hasta ponerlos en libertad a todos de la prisión en que por Norabroch estavan detenidos y darle a él castigo que por su crueldad y sobervia merecía, el qual no se levantaba de una silla, donde estava sentado vestido de brocado, ni alçarse quiso (342).

El regocijo del fin de fiesta coincide por último con la quema de la prisión que había apesadumbrado a los caballeros. Fuego y materiales efímeros se combinan para recrear el motivo BS. Incendio del castillo y puente de un caballero como castigo: tras la real cena y gran sarao «en un punto la peña y el padrón y castillo fue todo abrasado y ardido»».

El repaso a las circunstancias del torneo nos sitúa ante unos organizadores que han asimilado el funcionamiento de los motivos caballerescos y lo han aplicado sin tacha a su objetivo primordial: el encumbramiento del héroe y su reconocimiento como heredero de la dinastía. Proporcionan el entramado en el que los caballeros participantes pueden introducir sus variantes personales que, también por norma general, se ajustan a las marcas folclóricas del género o juegan con los personajes de sus libros favoritos ${ }^{60}$. Por ejemplo, la llegada el primer día de «una hermosa donzella muy ricamente vestida sobre un palafrén» se ciñe a lo consabido. Así lo explicita la crónica que nos la muestra dirigiéndose al enano para que le abra, pues «que venía a quexarse al cavallero del Griphón, agraviada de dos cavalleros. Abierta la puerta, con muchas lágrimas començó a se quexar que dos cavalleros, que sabía que

\footnotetext{
${ }^{59}$ BS. Desencantamiento permanente de un castillo encantado por caballero.

${ }^{60}$ Evidentemente la obra que se tiene en mente sobre cualquier otra es la de Montalvo: «Sabrá vuestra merced que el domingo siguiente se comenzó una extraña fiesta y fue que, imitando libros de Amadís, había una espada atravesada en un padrón de piedra...» comenta Cabanillas en su «Relación muy verdadera de las grandes fiestas que la Serenísima Reina doña María ha hecho al príncipe nuestro señor en Flandes, en un lugar que se dice Vince, desde xxii de agosto hasta el postrero día del mes. Enviada por el señor don Jerónimo Cabanillas, Medina del Campo, 18 de Noviembre, 1549», recogida en Relaciones de los reinados de Carlos Vy Felipe II, Madrid, Sociedad de Bibliófilos Españoles, 1950, pp. 199-221 (el texto en p. 207). A la elección de Beltenebros cabe añadir como mínimo la de Florestán, Angriote de Estravaus, Gavarte de Valtemeroso y Guilán el Cuidador. Este último fue asumido por Juan Quijada de Reayo, autor de la Doctrina del arte de la cavallería. Noel Fallows discurre sobre su participación en Binche, en su reciente e interesante libro: Jousting in Medieval and Renaissance Iberia, Woodbridge, The Boydell Press, 2010, pp. 42-56. Aparece también un curioso Guidón el Salvaje, procedente del Baldo. Lo que no quita para que cada espectador pueda proyectar sus lecturas sobre el desarrollo del torneo: «Non si vidde in quel giorno cosa brutta, se non che il Marchese di Berghes, giovane di 22 anni, e favorito de la Regina si pose alli piedi con un troncone di lancia Don Alonzo Pimentello altre volte chiamato Rodomonte, huomo che per fare professione di gagliardaccio, \& intervenendogli sempre qualche simile disgratia potrebbe ribattezarsi per Astolfo». p. 76
} 
venían a combatir con él, le avían querido hazer fuerça». La dramatización incide en la tópica aventura que exigiría unas ciertas dotes teatrales en la muchacha: «Muy congoxada estava la donzella y con poca esperança de verse vengada ${ }^{61}(333)$.

En otras ocasiones la contaminación con la ficción sentimental o el influjo de lo amoroso cancioneril se dejan sentir en las entradas en escena, como en la de este Caballero de la Muerte:

Viéronle baxar por los collados todo de negro con muchas muertes sembradas por el vestido, acompañado de muchos cantores vestidos de lo mismo que venían cantándole los responsos con muy suave y concertada música, y con la misma solenidad, después de vencido, lo acompañaron al castillo Tenebroso; éste era don García de Ayala ${ }^{62}$ (338).

Y no falta un curioso caso de convergencia con el romancero en la llegada de dos caballeros «úngaros vestidos de raso carmesí y amarillo con fluecos de oro con dos donzellas que les traían las lanças y Luisillo que venía tañendo y cantando A las armas, Moriscote. $\rangle^{63}$ Eran don Luis de Ávila y de Zúñiga, comendador mayor de Alcántara, y el Príncipe de Ásculi, quienes es muy probable que, al echar mano del motivo del viaje disimulado, quisiesen introducir alguna alusión a las pretensiones del hermano de Carlos con respecto al Imperio. Como sucede con el asunto central del torneo, también entre la aparente inocencia de las opciones personales de disfraz podían deslizarse implicaciones políticas de alto calado.

Mención aparte exige la elección de Felipe para presentarse en el torneo. Lo hace bajo el nombre de Beltenebros, máscara de Amadís en el episodio de la Peña Pobre (cap. XLVIII). Aunque se nos escapan las circunstancias anecdóticas de su estancia belga, no debemos olvidar que su condición de heredero viudo le pudo llevar a mostrarse como amante desolado, si no he-

${ }^{61}$ BS. Petición de ayuda a gritos por doncella; BS. Petición de ayuda a gritos de una doncella y mesándose los cabellos.

${ }^{62}$ En la relación complementaria de Cabanillas se lee: «salió un caballero español que le llaman don García de Ayala, hermano del conde de Fuensalida, que la noche antes se había desavenido con su dama; salió con muchos cantores delante cubiertos de luto, cantando responsos y él y sus caballos iban muy llenos de muertes; y así peleó como muerto, porque desde el primer arco lo llevaron a enterrar a él y sus cantores al castillo, que dio no poco placer» (p. 210). Para los entresijos folclóricos de estas apariciones caballerescas, véase ahora el muy documentado trabajo de Ana Carmen Bueno Serrano, «La experiencia de la muerte en el Primaléon como síntesis de tradiciones: la deuda del folclore», e Humanista, 16 (2010), 395-441.

${ }^{63}$ Véase Diego Catalán, Arte poética del romancero oral, Parte 1. ${ }^{a}:$ Los textos abiertos de creación colectiva, Madrid, Siglo XXI-Fundación Ramón Menéndez Pidal, 1997, p. 268 y Parte 2. ${ }^{a}$ : Memoria, invención, artificio, Madrid, Siglo XXI-Fundación Ramón Menéndez Pidal, 1998, p. 163 donde comenta la circunstancia de las fiestas de Binche. 
mos de suponer algún desengaño recientemente sufrido que le llevara a magnificarlo con el recuerdo de la más famosa penitencia de amor caballeresca ${ }^{64}$. Pero en realidad, para los buenos lectores de Montalvo debió de hacerse vivo el recuerdo de un famoso episodio del Amadís, concluido en las Sergas. Me refiero a las hazañas de Esplandián en la Peña de la Doncella Encantadora, cuando éste logra acabar con éxito el intento fallido de su padre en la Cámara Defendida. Juan Manuel Cacho ha observado que este mecanismo es «una de las constantes de la poética del género (...): de hecho es raro el libro de caballerías en que los hijos no pongan en olvido las hazañas de los padres $\rangle^{65}$. Lo que está muchas veces en la base de las continuaciones reales o simplemente prometidas y de la estructuración del género en ciclos viene aquí como anillo al dedo para la exaltación de Felipe como heredero de Carlos V. Se sanciona simbólicamente la continuidad de la dinastía y se augura la superación de sus logros en la figura del vástago. Aunque por razones obvias no se formula expresamente en ningún momento, la conclusión que puede extraerse del torneo pasa para un buen conocedor de los libros de Montalvo por las palabras de Sargil a Esplandián cuando lo ve descender de la Peña con la espada desenclavada al cuello: «Señor, mejor sois que vuestro padre; pues que esta aventura que él faltó vos la acabastes» ${ }^{66}$. Digno colofón a un episodio que había comenzado con el tono entre desenfadado y resignado del acompañante de Amadís en su fracaso: «Grasandor le dixo riendo y de buen talante: Descindamos de aquí y tornemos a nuestra compaña, que según me paresce, por un parejo llevaremos de aquí las honras y la vitoria deste viaje. Y dexemos esto para aquel donzel que comiença a subir donde vos descendís» ${ }^{67}$.

Recibido: 4/05/2011

Aceptado: 13/07/2011

\footnotetext{
${ }^{64}$ Kamen, apoyándose en la correspondencia del embajador francés, habla de los escarceos con una dama en particular, la duquesa de Lorena (ob. cit., p. 41).

${ }^{65}$ Juan Manuel Cacho Blecua, «La aventura creadora de Garci Rodríguez de Montalvo: del Amadís de Gaula a las Sergas de Esplandián», en Textos medievales: recursos, pensamiento e influencia, eds. Concepción Company; Aurelio González; Lillian von der Walde, México, Universidad Autónoma de México; Universidad Autónoma Metropolitana; El Colegio de México, 2005, pp. 15-50. La cita en pp. 41-42. La influencia del esquema de la Demanda del Santo Grial en este tipo de hazañas parece obvia: la gesta se construye sobre el modelo de Galaad, el hijo de Lanzarote, para quien se había reservado la aventura de la Queste.

${ }^{66}$ Garci Rodríguez de Montalvo, Sergas de Esplandián, ed. de Carlos Sainz de la Maza, Madrid, Castalia, 2003, p. 127.

${ }^{67}$ Garci Rodríguez de Montalvo, Amadís de Gaula, ed. cit. II, p. 1.708.
} 


\section{$\cos$}

RESUMEN: Análisis del torneo que se organizó en Binche en el verano de 1549 para ensalzar simbólicamente al príncipe Felipe como heredero de los Países Bajos. La justa se estructura en torno a una serie de aventuras prototípicas de los libros de caballerías y se intuye la influencia concreta del Amadís de Gaula. La poética del género no solo se difunde por medio de los escritos, también el espacio festivo es un ámbito que contribuye a dar a conocer sus constantes narrativas a un amplio público.

ABSTRACT: Study of the tournament held at Binche in the summer of 1549 and aimed to promote the figure of Prince Philip as the heir to the Low Countries. The joust follows the patterns of the typical adventures in the romances of Chivalry and a direct influence of the Amadis series is noticeable. The poetics of the genre is spread not only by means of printed books, but also with the help of festivals like this one that reached a wide public.

Palabras claves: Motivos folclóricos. Libros de Caballerías. Carlos V y Felipe II. Espectáculo caballeresco.

Keywords: Folk Motifs. Romances of Chivalry. Charles V and Philip II. Chivalric Festivals. 